\title{
"Cara ou coroa": uma provocação sobre educação para índios
}

\author{
Maria Helena Rodrigues Paes \\ Universidade do Estado do Mato Grosso, Departamento de Letras
}

\section{Introdução}

Quando me convidaram para escrever sobre a questão da educação indígena, neste volume que aborda Cultura, culturas e educação, a princípio tive sentimentos conflituosos, que flutuavam entre o entusiasmo e a temerosidade. Tomou-me o entusiasmo, tendo em vista minhas constantes discussões, mesmo que informais, com amigos e pesquisadores. Seria este o momento em que poderia ampliar minhas considerações sobre a questão, assim como tornar público algumas inquietações que poderiam também desconstruir posições já cristalizadas sobre o assunto. Mas, ao mesmo tempo, o temor invadia-me em função da possibilidade de considerarem minhas reflexões como busca de verdade ou tentativa de estabelecer uma nova forma de olhar que deveria prevalecer ao se pensar em educação para índios. Não me proponho a isto! Não pretendo ditar aqui, quaisquer que sejam, teorizações que sinalizem um rumo certo, um caminho para se fazer educação indígena. Quero apenas propor algumas reflexões que venham a provocar e ampliar cada vez mais o debate sobre esta questão, premente nestes tempos de atenção à diferença.

Trago neste texto algumas reflexões nascidas de oito anos de trabalho em educação com algumas comunidades indígenas de Mato Grosso, na região de Tangará da Serra, a noroeste deste estado. Servemme também, como principais ferramentas de reflexão, as discussões que se travaram no decorrer do desenvolvimento do Projeto Tucum - Programa de Formação de Professores Índios para o Magistério, executado no período de 1996 a 2000 no estado de Mato Grosso. Durante a execução desse projeto, minhas constantes inquietações derivavam de uma certa recusa da comunidade indígena Paresi de Tangará da Serra, em relação à implantação de um modelo de escola diferenciada ${ }^{1}$ nas aldeias. Investiguei essa questão em pesquisa de mestrado que resultou na disser-

\footnotetext{
${ }^{1}$ Utilizo este termo para me referir a um modelo de escola
} que pretendia a valorização dos aspectos culturais tradicionais de um povo, distanciando-se do modelo padrão do sistema nacional de ensino. 
tação intitulada "Na fronteira: os atuais dilemas da escola indígena em aldeias Paresi de Tangará da Serra - MT". ${ }^{2}$ No presente trabalho, trago partes ligeiramente modificadas dessa dissertação e apresento também algumas vozes de índios de comunidades do grupo Paresi, do município de Tangará da Serra-MT, então coletadas, para marcar e exemplificar minhas reflexões.

Não pretendo aqui retomar velhas discussões, abordando a necessidade, ou não, de as comunidades indígenas retomarem (como muitos defendem) suas formas tradicionais de vida, numa perspectiva saudosista. Muito menos desejo retomar discursos efusivos, da época das comemorações dos 500 anos, ${ }^{3}$ afirmando que temos uma dívida histórica com os povos indígenas deste solo que aprendemos a chamar "Brasil". Não nego a opressão e a humilhação destes povos que, ao longo da história, viram seus pares sucumbirem à ação de armas dos colonizadores, mas considero necessário entendermos o termo cultura numa perspectiva dinâmica. Por conseguinte, entendermos que os grupos e as identidades vão se constituindo a cada dia que passa, com o uso de novos instrumentos culturais e novas formas de relações com, e entre outra(s) sociedade(s). Sendo assim, não há como voltar ao passado, "resgatar" alguma coisa, como se as identidades fossem cristalizadas e estivessem no aguardo de algum "passe de mágica" para reaparecerem em sua forma "autêntica". Também não tenho a menor intenção de trazer para este espaço a velha discussão da relação "colonizador $x$ coloniza-

${ }^{2}$ A dissertação em questão foi defendida no Programa de Pós-Graduação em Educação da Universidade Federal do Rio Grande do Sul, na linha de Estudos Culturais em Educação, sob a orientação da Professora Rosa Maria Hessel Silveira, em 2002.

${ }^{3}$ Refiro-me às atividades comemorativas dos 500 anos do Descobrimento do Brasil, quando algumas organizações repudiavam as festividades preparadas pelo governo brasileiro, expressando a revolta com a forma desrespeitosa e, freqüentemente, violenta com que foram tratadas as populações indígenas na época e no decorrer dos acontecimentos históricos até hoje. do", "dominador $x$ dominado", relação em que um grupo simplesmente se sobrepõe ao outro, mesmo porque esta não é minha compreensão da relação entre grupos majoritários e minorias. Quero aqui deixar clara minha compreensão de que qualquer grupo, por menor que se configure, tem sua história cultural, e que todas as mudanças que se operam no seu interior, em função da inserção de novos artefatos e práticas culturais, constituem novos significados históricosociais, que por sua vez constituem e redimensionam a cultura. Assim, novos significados e representações de mundo vão se constituindo sem que se "descaracterize" o que alguns consideram a cultura tradicional. O que quero aqui desenhar e refletir se refere à compreensão de povos no contexto atual, dinâmico e em intenso movimento, que chamamos "mundo globalizado".

Nesta perspectiva, em se tratando de grupos indígenas, considero a escola como espaço e instrumento ímpar na constituição de novas subjetividades e significados de mundo, enquanto instituição que trabalha com regimes de verdade. Neste sentido, ela assume posição de destaque para análise e compreensão dos domínios simbólicos que, ao mesmo tempo, produzem e são produzidos pela cultura. Desta forma, minhas reflexões concentram-se basicamente em discussões sobre a relação destes grupos com esta instituição cultural, assim como com todos os elementos novos trazidos por esta.

Gostaria também de deixar claro que é inconteste a necessidade de se registrar que as diversas populações indígenas, atualmente, vivem em diferentes condições frente à comunidade não-índia. Umas já totalmente capturadas pelos códigos simbólicos ocidentalizados, inclusive pela língua portuguesa (para muitos, não são mais consideradas indígenas); algumas mantêm fortes suas expressões tradicionais de vida e costumes (muitas vezes, são erroneamente denominadas de "índios puros"); outras ainda vivem na fronteira entre essas duas caracterizações. Assim, entendo como imprescindível, ao se tratar da educação escolar nas aldeias, considerar a construção histórica e cultural de cada povo. 


\section{0 lugar de onde falo}

Para começo de conversa, considero necessário localizar o lugar de onde falo, o referencial teórico que reconstitui, a cada dia e a cada nova leitura, minha forma de olhar e de refletir sobre a questão da educação indígena; assim, fundamento-me nas linhas de autores pós-estruturalistas, especificamente falando, do campo dos Estudos Culturais. De aparecimento recente na história do pensamento na academia, esses estudos revelam-se atualmente como uma positiva alternativa de compreensão da cultura, não a partir de um eixo centralizador, mas sim de dentro da própria cultura, específica em si. Num movimento de rompimento com as metanarrativas, este campo de estudo se propõe a não considerar a ordem mundial sob apenas uma lente de olhar, desafiando as certezas e posicionando-se no campo da desconfiança e da dúvida.

Não há como negar a grande diversidade dos grupos humanos e, por conseguinte, não há como negar as diferenças que caracterizam cada grupo, muito menos se colocar em busca da homogeneização de todos eles, usando argumentos que se inclinam à idéia de igualdade entre todos. Não há mais como desconsiderar os saberes tradicionais e explicações de mundo de cada cultura somente pelo fato de se distanciarem das verdades padronizadas e aceitas pela ciência. Essa perspectiva iluminista acaba por descaracterizar a diferença, numa aceitação de padrões estéticos, políticos, religiosos, econômicos, educacionais etc., a partir das concepções dos grupos que se pretendem hegemônicos.

Dentro deste paradigma, o conceito de "verdade absoluta" cai por terra, surgindo novos regimes de verdade em diferentes posições no globo terrestre, em diferentes culturas. Configura-se, então, um amplo campo de análises e estudos, reunindo diversas posições teóricas e políticas, mesmo divergentes entre si, mas que se propõem a estabelecer análises culturais partindo do interior de suas relações de poder. Conforme indica Veiga-Neto (2000), para os Estudos Culturais "não há sentido dizer que a espé- cie humana é uma espécie cultural sem dizer que a cultura e o próprio processo de significá-la é um artefato social submetido a permanentes tensões e conflitos de poder" (p. 40).

Neste momento em que o mundo passa por intensos processos de mudança ante os procedimentos com tendências homogeneizadoras decorrentes da globalização, ao lado da eclosão de conflitos étnicos insuspeitados, os Estudos Culturais nos fornecem ferramentas imprescindíveis para compreensão das (re)constituições das identidades individuais e culturais. Na perspectiva dos Estudos Culturais, não há mais como se pensar em identidades culturais unificadas, já que a "identidade plenamente unificada, completa, segura e coerente é uma fantasia", como afirma Hall (2000, p. 61). Assim, este campo de estudos nutre-me de abordagens que permitem olhar a educação indígena a partir de perspectivas particularizadas. Não em sentido relativista, devo esclarecer, mas fornecendo-me ferramentas para refletir a partir da história de uma determinada cultura sem a necessidade de estabelecer comparações, ou mesmo sem a necessidade de me ancorar em experiências publicadas e reconhecidas nacionalmente ou mesmo internacional. Deixo bem claro, mais uma vez, que as reflexões que aqui trago não têm desejo de verdade, mas se colocam em uma dimensão questionadora e de desconfiança.

\section{Cultura: raízes culturais versus exigências do global}

A princípio, quando pensamos ou falamos sobre cultura, nos parece que se trata de um conceito tão comum que não nos damos conta do quão difícil e controverso é tentar defini-lo; na verdade, ele tem sido tema de muita teorização e polêmicas. Porém por mais difícil que se revele trilhar por este caminho, sinto-me impelida a buscar algumas reflexões sobre multiculturalismo e hibridismo, indicando quão "misturados" somos em nossa vida em sociedade, de forma que estamos continuamente reorganizando estruturas e valores tidos como tradicionais. O pro- 
cesso de globalização torna o mundo menor do que as nossas representações tradicionais de tempos e espaços. As fronteiras mostram-se mais flexíveis, permitindo fluxos migratórios cada vez mais freqüentes e provocando um inevitável processo de miscigenação.

A ciência tem desenvolvido instrumentos e técnicas refinadas de forma acelerada, oferecendo uma série de recursos tecnológicos que produzem inúmeras transformações no mundo padronizado, idealizado pela modernidade. Por outro lado, os meios de comunicação de massa invadem os territórios de todas as nações, por menores que sejam, fragilizando fronteiras, miscigenando culturas. O ideal de uma "cultura pura" e as verdades que se pretendiam essenciais e universalizadas estremecem diante das novas imagens estampadas nos meios de comunicação de massa e do crescente processo migratório, aos grandes centros urbanos, de pessoas em busca de melhores condições de vida, levando a metamorfoses culturais e sociais. As mudanças de costumes, o contato com novos regimes de verdade, a introdução de formas de utilização de novos objetos e artefatos, de novas linguagens globalizadas, configuram a nova ordem mundial.

Stuart Hall (1997) aborda o tema cultura, afirmando que esta é produzida através da representação, em que a linguagem, um sistema de significados partilhados, desempenha papel central no estabelecimento de sentido das práticas e valores culturais. Desta forma, a cultura não é dada ou herdada, mas construída, num movimento contínuo de construção e reconstrução, nas práticas rotineiras das pessoas de um determinado grupo. Nesta perspectiva, a cultura não é finita, mas é aberta e fluida, como num movimento das ondas do mar que se renovam a cada lamber nas areias da praia. A cada novo toque, ondas e areia renovam-se e completam-se em novos significados. Nas próprias palavras de Hall, "a cultura depende de que seus participantes interpretem de forma significativa o que esteja ocorrendo ao seu redor e 'entendam' o mundo de forma geral semelhante" (idem, p. 2).
Na perspectiva dos Estudos Culturais, Costa (2000), inspirando-se também nas palavras de Hall, opta por conceituar cultura como "o terreno real, sólido das práticas, representações, línguas e costumes de qualquer sociedade histórica específica” (p. 40). Essas abordagens nos apontam um caráter dinâmico de cultura, indicando a fluidez de identidades que são negociadas nas relações sociais, que por sua vez ressignificam o próprio mundo ao redor. Essa magia do fazer/refazer, significar/ressignificar num movimento contínuo configura novas formas de interpretação de mundo que vão definindo as expressões culturais. Em suma, a cultura é uma construção através das práticas representativas.

Não penso em culturas "presas" a descrições antropológicas ou presas a passados tradicionais e (pré)históricos, que inscrevem seus cidadãos em uma moldura de "formas características" e inertes de ser e viver. As pessoas fluem dentro de seus territórios sociais e para fora deles, trocam informações, ensinam e aprendem novas formas de se expressarem e de significarem o mundo a seu redor, desenhandose, assim, formas híbridas de culturas e, por conseguinte, de identidades.

Néstor Canclini, em Culturas híbridas, trata a questão da miscigenação de culturas frente ao crescente processo de fluxos migratórios, afirmando que inúmeros elementos provocam efeitos híbridos nas populações, como a midiatização e o crescimento populacional urbano.

Passamos de sociedades dispersas em milhares de comunidades rurais com culturas tradicionais, locais e homogêneas, em algumas regiões com fortes raízes indígenas, com pouca comunicação com o resto de cada nação, a uma trama majoritariamente urbana, em que se dispõe de uma oferta simbólica heterogênea, renovada por uma constante interação do local com redes nacionais e transnacionais de comunicação. (Canclini, 1997, p. 285)

Não há mais como se pensar em comunidades e sociedades isoladas e puras em sua cultura, também aponta Sarlo, ao discutir os efeitos da mídia sobre 
culturas populares e, acrescentaria aqui, sobre as culturas das minorias étnicas antes isoladas em comunidades com poucos contatos com o exterior. A autora sustenta que não há como se fechar os olhos para a miscigenação de elementos culturais provocados pela disseminação da mídia. A inserção destes meios comunicativos reconfigura as características específicas de culturas locais diante do acesso às imagens de televisão, que quebram as barreiras do tempo e espaço: "o tempo na cidade e do espaço campestre, antes separados por distâncias semanalmente produzidas pela estrada de ferro, os jornais e os livros, agora são tempos sincronizados", afirma Sarlo (1997, p. 102), fazendo referência ao tempo em que os meios de comunicação se revelavam incipientes para dar conta da veiculação de informações em um curto espaço de tempo.

A tecnologia, principalmente através do rádio, da televisão e da Internet, oferece oportunidades a grupos - por mais longínquos que se encontrem geograficamente - de se posicionarem diante de eventos em outros locais e de tomarem conhecimento, a partir de uma determinada versão, de fatos ocorridos a quilômetros de distância, ao mesmo tempo em que eles ocorrem, não importando a diferença de contexto em que se situem os telespectadores. Os meios de comunicação, assim, colocam-se como instrumentos de ligação entre povos de diferentes construções simbólicas e valores culturais, situando os diferentes sujeitos, em diferentes espaços, numa mesma condição - a de telespectadores.

Em um mundo onde a informação se configura em instrumento de inserção, presença e afirmação de identidades, a mídia se fortalece como artefato de subjetividades, conforme nos indica Sarlo (1997), ao se referir às minorias étnicas que capturam as novas formas de como se comportar nesse mundo globalizado, assumindo para si as ferramentas discursivas necessárias para compor um novo espaço; assim, “os índios aprendem rapidamente que, se quiserem ser ouvidos na cidade, devem usar os mesmos meios pelos quais eles ouvem o que se passa na cidade" (p. 101).
Desta forma, os índios e outras minorias transformam seus tradicionais meios de vida para se sentirem inseridos neste mundo que gira e funciona sob o eixo da informação, provocando mudanças na configuração de suas identidades. Neste aspecto, ao tratar da questão da construção de identidades, Hall (1997) se mostra perspicaz ao observar:

\begin{abstract}
[...] o que denominamos de "nossas identidades" poderia provavelmente ser melhor conceituado como as sedimentações através do tempo daquelas diferentes identificações ou posições que adotamos e procuramos "viver", como se viessem de dentro, mas que, sem dúvida, são ocasionadas por um conjunto especial de circunstâncias, sentimentos, histórias e experiências única e peculiarmente nossas, como sujeitos individuais. Nossas identidades são, em resumo, formadas culturalmente. (p. 26)
\end{abstract}

Retomando Hall (2000), que considera a globalização um processo promotor da compressão espaçotempo, de forma que se perceba o mundo menor do que realmente é, e as distâncias como praticamente inexistentes, pode-se afirmar que os meios de comunicação de massa e a alta tecnologia investida em meios de transportes promovem a facilidade de fluxos entre diferentes grupos e culturas. A sedução das metrópoles com maior potencial de desenvolvimento, que prometem perspectivas de melhoria de "qualidade de vida", captura populações que se encontram na periferia e passam a afluir aos grandes centros.

Ao saírem de seu locus cultural de origem, passam a adotar, de alguma forma, costumes, tradições e línguas diferentes. Salienta Hall (2000) que ocorre um movimento, ao qual chama de tradução, caracterizado pelo fato de o sujeito habitar, transferir-se e transportar-se entre fronteiras, vivendo na fronteira de duas culturas diferentes. O sujeito não "pertence" ao lugar que está habitando e nem mais pertence a seu lugar de origem, tendo que desenvolver formas de transitar entre os dois mundos: "eles devem aprender a habitar, no mínimo, duas identidades, a falar duas linguagens culturais, a traduzir e a negociar entre elas" (p. 87-89). 
Canclini (2000) afirma que o reconhecimento da hibridação modifica o modo de se abordar, discutir e compreender, entre outros, o conceito de identidade e de cultura. Definindo hibridação como abrangendo "procesos socioculturales en los que estructuras o práticas discretas, que existían en forma separada, se combinan para generar nuevas estructuras, objetos y prática" (p. 2), afirma ainda que este processo se dá até de forma improvisada, não planejada - devido a fatores como trânsitos migratórios, viagens turísticas ou mesmo através do intercâmbio econômico e comunicacional - mas que resulta em construções criativas, individuais e coletivas. Nesse sentido o autor comenta o processo de reconversão, explicando que este termo se refere ao processo de criar estratégias de forma que os indivíduos se situem e transitem em situações novas, como, por exemplo, "os movimentos indígenas que reinsertan sus demandas em la política transnacional o en un discurso ecológico, y aprenden a comunicarlas por radio, televisión e Internet" (p. 3). Assim, Canclini entende que os processos de hibridação é que devem ser o centro de esforços de estudos sistemáticos, e não a hibridez em si. Nesta perspectiva, não importa o quão híbridos sejam os sujeitos, mas sim como se constituem desta forma. A discussão não se concentra, então, em juízos de valores quanto a ser puros ou impuros, ou mesmo em "perdas de identidade", mas em compreender os processos que (re)constroem as identidades dentro de novos contextos, novas configurações sociais.

Desta forma, compreendemos que as identidades são artefatos abertos e flexíveis, concordando com Hall (2000) quanto aos impactos da homogeneização globalizante, no sentido de que "a globalização tem, sim, o efeito de contestar e deslocar as identidades centradas e fechadas" (p. 87), concebendo-as como plurais, mutantes e diversas.

Em toda parte, estão emergindo identidades culturais que não são fixas, mas que estão suspensas, em transição, entre diferentes posições; que retiram seus recursos, ao mesmo tempo, de diferentes tradições culturais, e que são produto desses complicados cruzamentos e misturas culturais que são cada vez mais comuns num mundo globalizado. (Hall, 2000, p. 88)

Desta forma, entendo que a questão da miscigenação não se configura em aspecto negativo como representações de "perdas"; ao contrário, trata-se de dinâmicas de (re)construção, (re)significação de mundo e de sujeitos, assim como de (re)posicionamentos em tempos e espaços.

\section{0 índio globalizado}

São diferentes as configurações dos mais de duzentos grupos indígenas espalhados pelo território brasileiro, sendo que um grande número destes já vive sob forma híbrida, embora nem por isso deixem de ser legalmente índios. O processo de contato com a sociedade não-índia inseriu novos costumes e novas formas de utilização de utensílios de uso rotineiro, assim como trouxe novos instrumentos para uso nas aldeias, inventados e utilizados pela sociedade envolvente. Onde antigamente havia somente casas construídas de materiais retirados da natureza, em dias atuais é comum as casas serem construídas de madeira ou mesmo de tijolos. Atualmente também utensílios domésticos industrialmente manufaturados são adquiridos no comércio das cidades e levados para as aldeias.

Especificamente a partir da minha experiência de convivência com a comunidade Paresi, observei que, em se tratando da roça, que em sua forma tradicional centra-se em atividades comunitárias para plantio e colheita de subsistência, em função do contato com os não-índios os índios foram capturados pelas novas formas de cultivo da terra, sendo incorporados à rotina da roça utensílios como enxada, pá, arado, rastelo etc. Com a expansão da lavoura mecanizada em terras vizinhas à área da reserva indígena, os índios passaram também a utilizar tratores e pesados equipamentos agrícolas, às vezes por empréstimo dos fazendeiros ou mesmo por pagamento da empreitada, para manuseio da terra, na época do preparo para 
o plantio, ou ainda na colheita. Alguns grupos já se encontram organizados em forma de associações, o que lhes oportuniza a aquisição de maquinário agrícola, como tratores e colhedeiras para manuseio de suas roças.

Outro aspecto que chama muito a atenção se refere à inserção dos aparelhos eletrônicos no interior das casas das aldeias. O rádio, normalmente de freqüência $\mathrm{AM}$, é peça comum em inúmeras casas, e por ele os índios acompanham as informações de sua região, do país e também do mundo, além de seguir os sucessos musicais de suas preferências. A televisão também marca presença em muitas aldeias, tanto por aquisição particular de alguns moradores como através do programa de distribuição do Kit Tecnológico ${ }^{4}$ assim, eles acompanham a programação das redes nacionais e assistem a filmes locados nas cidades. Os aparelhos de som, para fita K-7 e discos, também são freqüentemente encontrados nas casas das aldeias.

Além do rádio amador, o sistema de telefonia fixa tem se expandido também para várias aldeias do país, e o telefone celular é a mais nova invenção eletrônica a desembarcar no território indígena. Estes mais novos componentes eletrônicos colocam os índios, nas aldeias, em situação de comunicação rápida com qualquer outra região. Do centro de suas aldeias os índios recebem e enviam informações, assim como tratam de negócios e procuram resolver problemas da comunidade imediatamente. Algumas aldeias servidas por redes de energia elétrica e de telefonia acessam a Internet diariamente, comunicando-se com o mundo e tendo acesso às notícias dos últimos acontecimentos, onde quer que ocorram.

\section{A questão da escolarização dos índios}

Com as intensas mudanças nos paradigmas de compreensão de mundo que vêm povoando nossas

${ }^{4}$ Programa do MEC que distribui aparelhos de televisão, videocassete, antena parabólica e codificador de sinais para escolas com mais de 50 alunos. preocupações, a visão de escola e de sujeito do conhecimento também passa por um redimensionamento. Enquanto a modernidade nos acenava com a perspectiva do sujeito centrado, disciplinado, e um mundo cuja perfeição dependia de soluções racionais partindo da ação humana, o pensamento pós-estruturalista vem romper com a visão universalista da perfeição e dos enquadramentos de saberes científicos e disciplinados. Nesta perspectiva, a escola, de caráter ocidental, também sofre os abalos e os estilhaços de pensadores que se dispõem a problematizar a estrutura de organização e movimentação da sociedade.

Em se tratando de Brasil, o contato entre índios e não-índios iniciou-se num período marcado pelo pensamento moderno do desenvolvimento em busca de um saber universal e de ênfase na igualdade de condições, sendo a postura disciplinar - de normas rígidas e de controle absoluto dos comportamentos a tônica das trajetórias escolares implementadas por missões religiosas da época e que se efetivaram ao longo da história. Dessa forma, o processo escolar que os índios vieram a conhecer baseia-se nesta perspectiva: na crença de uma suposta superioridade de um saber verdadeiramente científico e confiável, ao qual mesmo muitas pessoas da comunidade não-índia também ainda não têm total acesso. $\mathrm{O}$ mundo que está construído em volta das aldeias é um mundo moderno, baseado nos saberes da ciência e tecnologia, e é através do conhecimento escolar que se pensa e se pretende dominar esses saberes. Ao longo de meu trabalho com as comunidades indígenas, percebi, em conversas informais, que os índios têm a visão de que é por meio da escolarização de cunho tradicional, com todos os seus referenciais de verdades, que os não-índios podem chegar a ser advogados, engenheiros agrônomos etc., que, por sua vez, são títulos e posições de status valorizado, construídos nesta sociedade de caráter capitalista. Para eles, então, assim como para muitas pessoas da sociedade ocidentalizada, a escola se configura como um instrumento indispensável para ascensão social e profissional.

Em contraposição, atualmente muitos são os mo- 
vimentos, tanto nacionais quanto internacionais, que trabalham na defesa das especificidades das culturas indígenas. São movimentos que buscam assegurar a valorização da pluralidade e o direito de cada cultura no sentido de possibilitar a sobrevivência de suas características próprias, sendo a escolarização um dos processos mais questionados. Dessa forma, já nos anos de 1970 surgiram movimentos de professores indígenas que produziram documentos escritos - o mesmo instrumento utilizado pela sociedade civil organizada - para garantir o direito de uma educação específica às suas realidades. Como resultado desses debates, em nível nacional, a Constituição Federal de 1988 rompe radicalmente com o paradigma integracionista e, através dos arts. 210, 215, 231 e 232, assegura às comunidades indígenas o direito à diferença e à autonomia, delegando ao Estado a salvaguarda desses direitos.

Com a referida Constituição, então, novas discussões se desencadearam, de forma que decretos e portarias foram sendo incorporados à lei maior, garantindo e regulamentando as ações de Educação Escolar Indígena, em todo o Brasil, destacando-se as Diretrizes e Bases para a Política Nacional de Educação Escolar Indígena. Em 1988, o Ministério de Educação publicou o Referencial Curricular Nacional para as Escolas Indígenas (RCNEI). Estes novos fundamentos pretendem assegurar a implantação de estruturas escolares em consonância com as características de cada povo, no sentido de valorizar os aspectos da comunidade na concepção de currículos específicos, bem como a "liberdade de decisão quanto ao calendário escolar, à pedagogia, aos objetivos, aos conteúdos, aos espaços e momentos utilizados para a educação escolarizada" (Brasil, MEC, 1998, p. 24).

A nova concepção de escola indígena inscrita no RCNEI traz a "interculturalidade" como aspecto de relevância na rotina pedagógica, no sentido de respeitar a diversidade cultural de forma a não sobrepor uma cultura à outra, mas sim valorizar as trocas de experiências interculturais. Neste sentido, a língua materna assume importância ímpar nas novas configurações escolares em aldeias indígenas, como elemento essencial na manutenção e valorização dos aspectos culturais de cada povo.

É comum se encontrar nas comunidades indígenas muitas pessoas opinando que a escola da aldeia tem que ensinar às crianças "as coisas do branco, pois as coisas de índio eles aprendem com a família e a comunidade". ${ }^{5}$ Dessa forma, há bastante discordância a respeito de como encaminhar as atividades na escola da aldeia, principalmente considerando as últimas discussões e publicações e projetos sobre educação indígena que buscam privilegiar e valorizar o saber e práticas pedagógicas da cultura tradicional local.

\section{0 que é a escola para os índios?}

Em meu trabalho de acompanhamento às escolas nas aldeias, fui percebendo que a escola possui uma tarefa muito particular para os habitantes daquelas comunidades e que meu referencial de "boa escola" não coincidia com o referencial construído por aquela população.

Há que se lembrar que a perspectiva e a proposta que temos hoje de escola do sistema de educação nacional e suas funções, quanto à formação de cidadãos críticos, políticos e conscientes - discurso mais corrente de norte a sul em nosso país - vêm sendo construídas em nossas sociedades através de muitas discussões nas últimas três décadas, sem, no entanto, dar conta, ainda, de cobrir todas as ações em todas as esferas da comunidade escolar nacional, no sentido de provocar mudanças efetivas. Por mais que os educadores discutam e formulem propostas "inovadoras", é comum ainda percorrermos inúmeras escolas e encontrarmos metodologias e currículos de cunho bacharelesco, preocupados com acúmulos e repetição de conteúdos dentro de um modelo tradicional.

Considere-se que os índios tiveram que desenvolver novas e diferentes tecnologias para os conta-

\footnotetext{
${ }^{5}$ Retirado de meus registros de caderno de campo.
} 
tos junto aos não-índios que traziam inúmeras novidades, entre elas, a representação gráfica do que se falava. Foram aos poucos conhecendo a "magia" das letras impressas no papel e descobrindo sua necessidade diante da nova realidade, junto aos homens de outros e diferentes costumes. Lembra-nos Bandeira (1997) que "assim aprendem a escrita como uma entre outras tecnologias da cultura envolvente, mas com interesse especial de aplicações no adentramento da organização jurídico-burocrática da sociedade envolvente (p. 40).

Bonin (1998) afirma que "o conhecimento 'de fora' assume, no contexto do contato, um caráter novo: é algo que precisa ser procurado, cercado e dominado" (p. 140). Desta forma, a condição de compreensão dos códigos ocidentais foi se efetivando como componente necessário à sobrevivência dos índios, que foram sendo capturados pelo discurso da "escola necessária”, de que a escola se instituía como único (ou mais importante) instrumento de possibilidades de adentrar este mundo novo.

Não vamos levar a vida assim como agora, cada vez nós estamos... assim... ficando mais próximos do branco... E o branco mais próximo de nós, apertando mais ainda, então a gente pode levar os alunos, a criançada a aprender mais, conhecer mais a escrita... como podem se defender... como levar as pessoas mais velhas que não sabem ler, ajudando elas na cidade, como redigir os documentos...

(Pai de aluno)

Nesta perspectiva, conhecer e dominar elementos da dinâmica do mundo ocidental apresenta-se como importante ferramenta para manutenção e sobrevivência da comunidade e, como afirma Bonin (1998), a escola deve configurar-se "como uma possibilidade neste processo de apropriação do conhecimento 'de fora'. Apropriar-se de novos saberes não significa sobrepô-los ao saber tradicional, mas transformá-los em 'caixas de ferramenta'" (p. 141). A escola, então, como instrumento de acesso aos saberes ocidentalizados, apresenta-se como essencial no interior destas comunidades, com objetivo de trans- mitir os códigos simbólicos da sociedade envolvente, com a qual as relações se tornam cada vez mais estreitas, não querendo o índio estar alheio à realidade nacional. Ele quer e precisa participar da dinâmica da sociedade brasileira; desta forma, a escola "adquiriu um importante valor instrumental: ir à escola facilita a aprendizagem de novas habilidades e conhecimentos sobre o mundo exterior, necessários para a sobrevivência" (Arellanos \& Freedson-Gonzáles, 1998, p. 92, tradução minha).

Compreendo que os índios esperam que a escola cumpra a função de trazer informações sobre a dinâmica da sociedade envolvente, assim como sobre os códigos dos instrumentos ocidentais que, agora, fazem parte das dinâmicas de suas comunidades. Considerando inevitáveis as relações com o mundo ocidentalizado, há que se ressignificar as rotinas de forma a compreender e lidar com os novos instrumentos, utilizar as mesmas tecnologias do mundo ocidental para negociar suas necessidades de sobrevivência. Participar da sociedade envolvente, participar do mundo gestado e mantido hoje pela escrita e pela tecnologia reconstrói e ressignifica o ser índio, que não quer e não pode estar alheio e marginalizado neste novo movimento. Como outras populações isoladas e minoritárias que tomam contato com a cultura ocidentalizada, também querem estar inseridos nesta dinâmica de sociedade global. Não há como estar inserido em um contexto sem conhecêlo, assim como não há como participar de uma dinâmica social sem conhecer os códigos que a regem.

O índio sente-se ameaçado diante de tantas mudanças, construindo um significado de que a formação acadêmica e a profissionalização de pessoas da comunidade se colocam como imprescindíveis para seu posicionamento diante dos códigos que regem a sociedade envolvente. Não conhecendo e compreendendo os códigos normativos e legislativos, estarão sempre na dependência de "outros" para a garantia de seus direitos, para terem a certeza de não serem enganados. Nesse sentido, justifica-se a construção da representação de que um advogado ou um juiz de direito do próprio povo reverteria esta situação. A 
representação da escola se constitui como instrumento de defesa, na perspectiva de compreender os códigos da sociedade do "outro", para estabelecer relações com esta, usando seus instrumentais legítimos com objetivo de se "proteger" de possíveis "enganos". Com o domínio destes instrumentos eles entendem que podem garantir sua sobrevivência, sem risco de que as organizações governamentais, através de instrumentos jurídicos legais, provoquem a perda de suas reservas, por exemplo.

\section{Escola: a estrangeira}

Em meu contato com índios percebo que estes colocam a relação índio $x$ não-índios numa perspectiva dicotômica, localizando a escola como pertencente ao civilizado. Essa dicotomia fica evidente nas expressões usadas por uma pessoa entrevistada, contrapondo sabedoria tradicional - "sabedoria nossa, é a questão tradicional" - ao saber circulante na escola, o saber do civilizado, deixando claro que a escola da aldeia não é escola indígena. Nesse sentido, a escola tem a função e deve se estruturar como instrumento de transmissão dos códigos simbólicos do mundo civilizado.

$\mathrm{Na}$ perspectiva do que abordei nos parágrafos anteriores, apontando a participação e os significados dos movimentos indígenas, Bonin (1998) nos fala sobre a aquisição do conhecimento formalizado enquanto poder do não-índio, localizando-o como instrumento de luta:

É necessário compreender a estrutura, decifrar as regras da sociedade dominante, conhecer os mecanismos legais de garantia dos direitos, compreender a política oficial para os povos indígenas, ter acesso às informações, enfim, apropriar-se de um instrumental que lhes assegure a autonomia. (p. 139)

Para participar das dinâmicas construídas pela sociedade nacional, as minorias reestruturam-se e ressignificam-se, com instrumentos próprios e adquiridos, negociando sua posição rotineiramente nas re- lações sociais. Admitir a escola na aldeia, com todos os seus rituais de saberes e valores ocidentalizados, pode não significar a submissão e rendição à homogeneização cultural destes grupos; ao contrário, pode representar uma ação de resistência a este processo, como nos alerta Silva (2000), que entende a escolarização para as comunidades indígenas como instrumento e forma de decifrar a realidade frente à situação de contato, e afirma que este ato, "longe de ser uma 'adesão' (simples) a nosso modelo, é, nesse sentido, uma estratégia de resistência” (p. 65). Esta postura também é compartilhada por Bonin (1998): "Decifrar este mundo e as regras nas quais se estrutura o sistema de dominação é, então, estratégia de resistência. $\mathrm{O}$ conhecimento nestes termos é instrumento para os povos indígenas na luta para a mudança nas relações com a sociedade envolvente" (p. 140).

A escola como instrumento para "defesa da comunidade" teria uma função, sobretudo, de resistência, no sentido de que, compreendendo os códigos da cultura envolvente, não só a comunidade indígena conseguiria transitar nesta realidade como também negociaria com os mesmos instrumentos e dinâmicas, marcando sua forma diferente de viver numa sociedade multicultural, mas que se revela homogeneizante sob a perspectiva da oferta de oportunidades. Conhecer e compreender os códigos que regem a sociedade envolvente não significaria simplesmente render-se a eles (embora, em longo prazo, eles viessem a ser naturalizados também em tais comunidades), mas seria imprescindível entender os mecanismos de sua dinâmica, com o propósito de lidar com os mesmos, de forma que passem a ser seus estes mesmos instrumentos de negociações. Incluídos, presentes na história da sociedade nacional sem, no entanto, deixar os costumes tradicionais, ou ao menos alguns, os índios se fariam respeitar pela diferença, utilizando os mesmos instrumentos característicos da sociedade ocidentalizada: a palavra escrita, organizações jurídicas, o poder do conhecimento universalmente reconhecido etc.

Compreendo que os índios vêm claramente as novas instrumentalizações de que necessitam para 
negociar seu trânsito e permanência nas dinâmicas da realidade da sociedade envolvente. É necessário preparar-se para adentrar estas dinâmicas, caso contrário, danos serão sentidos pela comunidade como um todo. A sociedade ocidentalizada se organiza legalmente através de registros e documentos oficiais, e, com o intenso contato e estabelecimento de relações comerciais com esta sociedade, os índios deveriam apreender estes códigos, que se fazem necessários diante das novas exigências.

Bom... eu acho que futuramente a escola pode... Pode ajudar, né? Porque... Por isso a criança tem que passar na escola ainda... Pra estar conhecendo primeiro a escrita, como tem que fazer, e... Conhecendo o papel, o seu papel que está fazendo, que está assumindo, né? Se não conhecer o papel que está fazendo, aí fica muito difícil, porque a... As lideranças todas as vezes que fazem reunião com as organizações, eles não têm nenhuma documentação, nenhum relatório pra estar... cobrando. Daqui mais algum tempo, né? Então isso é uma grande dificuldade das lideranças. (Professor índio de escola da aldeia)

A gente vem preocupando com a comunidade e o futuro das comunidades porque, como hoje, no tempo presente tem muitos dirigentes das aldeias, que tem, assim, muita dificuldade de procurar seus direitos, de agir na frente das autoridades e procurar uma alternativa de melhoria de sua comunidade. Tem tudo isso, né? Então a gente vem preocupando com as demais coisas ainda. (Professor índio de escola da aldeia)

As dinâmicas políticas, sociais, econômicas da sociedade ocidentalizada organizam-se num sistema de escrita que marca o que é legítimo e o que não é. As lideranças das comunidades já não mais negociam à base de lutas corporais, conflitos interétnicos; em função de as atividades, cada vez mais ocidentalizadas, inserirem-se nas rotinas diárias, faz-se presente a necessidade de diálogos e negociações com a sociedade envolvente. Projetos devem ser elaborados para aquisição de maquinários agrícolas, medicamentos e equipamentos de saúde, ações de saneamento das aldeias, provimento de água mais próximo às casas, bem-estar de direito de qualquer cidadão brasileiro, e eles necessitam de encaminhamento burocrático para sua aprovação e implantação. Nas instâncias de órgãos oficiais de financiamento para a concretização destes direitos, a oralidade ou a escrita não-normatizada não tem valor jurídico reconhecido para sua obtenção, mesmo que conste em lei que essa obtenção é direito de todos

Para o acesso a estes bens de direito, atualmente as comunidades, através de seus líderes, contam com a intermediação de funcionários de órgãos oficiais, ainda dependendo de serviços prestados por estes. Insatisfeitos com tal dependência e desejando assumir o direcionamento de ações relacionadas a seu povo, eles percebem a urgência da necessidade de informações, precisando instrumentalizarem-se tecnicamente, através da leitura e escrita, para conduzir seus próprios processos de construção do bem-estar de suas comunidades.

É fato o descontentamento de um povo que, desde o contato com o não-índio, esteve subjugado historicamente a restrições e determinações oficiais que o levaram a uma situação de dependência, principalmente por não disporem de instrumentos técnicos para compreensão e subseqüente negociação da construção de suas próprias trajetórias, segundo seus desejos e anseios. Nesta perspectiva, a escola constitui-se como fonte principal de instrumentalização técnica da leitura e escrita que lhe acenará com as possibilidades de acesso aos conhecimentos.

\section{A disciplina e rotina escolares}

Os grupos indígenas brasileiros tiveram contato com uma instituição escolar de princípios iluministas, com objetivos assimilacionistas no sentido de "tornálos civilizados" para o bom convívio com a sociedade ocidentalizada; para tal, o controle disciplinar sobre o corpo, a docilização deste, fazia-se imprescindível. A proposta de uma "escola específica e diferenciada", que se apresente minimamente coercitiva, propondo respeitar e valorizar a cultura tradicional e saberes lo- 
cais, é uma construção processual recente entre estes povos, ainda em construção de significados.

Ao falarem da situação de escolarização atual, os índios deixam claro que não acreditam que a escola venha cumprindo seu papel enquanto produtora de saberes que os leve à situação de igualdade em relação aos não-índios, e apontam a falta de interesse das crianças pelas atividades escolares como um dos fatores causais deste fenômeno. Neste sentido, recorrem à ineficiência do dispositivo disciplinar que, embora coercitivo e punitivo, estaria deixando de controlar "adequadamente" o comportamento dos alunos em sala de aula.

A representação da construção do saber com base na disciplinarização dos corpos parece-me clara nas falas das pessoas que entrevistei. Nessa perspectiva, estabelecem comparação, numa relação temporal antigamente/atualmente - referindo-se à configuração da escola de princípios modernos que, através de procedimentos disciplinares, controlava e assegurava a permanência do aluno nas atividades escolares, enquanto que nos dias atuais esse procedimento não viria se efetivando:

Mas hoje em dia a gente está tentando com essas crianças, quase que eles não aprendem porque eles não ficam prestando atenção, quando a gente fala, quando a gente conversa com eles, eles abaixam a cabeça, ficam só desenhando, não escutam nada... e quando a gente fala com os alunos eles não prestam atenção, pegam o estilingue vão pra fora, ficam brincando atrás de passarinho, pegam flecha, brincando, por isso não aprendem. (Professor índio de escola da aldeia)

Observei que o Paresi acredita na relação causa/ consequiência do binômio "disciplinarização $x$ aprendizagem", conforme preconizavam os ideais iluministas de educação, que implicavam produzir um sujeito organizado, disciplinado para estabelecer relações num mundo, também organizado, de bases normativas. Assim, a escola teria a função de disciplinar, organizar a sociedade diante das novas relações, tirando do aluno o estado "puro", "natural”, instrumentalizando- o para o convívio com a sociedade envolvente. Tratando da escola enquanto produtora de sujeitos disciplinados, Veiga-Neto (2001) se vale das palavras de Kant para afirmar que "disciplinar quer dizer: procurar impedir que a animalidade prejudique o caráter humano, tanto no indivíduo como na sociedade. Portanto, a disciplina consiste em domar a selvageria" (p. 11). Posso ainda me utilizar de Foucault (2000), que trata a disciplina como abrangendo os "métodos que permitem o controle minucioso das operações do corpo, que realizam a sujeição constante de suas forças e lhes impõem uma relação de docilidade-utilidade" (p. 118). Na perspectiva aqui discutida, os índios entrevistados foram interpelados pelo discurso da "ordem do mundo", no qual a escola se fundamenta com princípios e ações disciplinares, capturando o sujeito de modo a produzi-lo segundo a perspectiva normativa da sociedade hegemônica, e assim se sentir pertencente a ela.

Considerando que a maioria dos índios brasileiros estão numa condição de minoria étnica, mas constantemente interpelados por discursos da sociedade majoritária, que, por sua vez, conferem valor e status social ao indivíduo que cumpre com os requisitos de uma norma, construída culturalmente, a "disciplina", para este povo, passa a representar uma das ferramentas que permitirá ascender socialmente nesta sociedade. Portanto, entendem que a escola deve trabalhar no sentido de produzir comportamentos disciplinares, aceitáveis, que conduzirão futuramente os alunos à condição de cidadãos "civilizados": cidadãos da sociedade nacional, que cumprem rigorosamente as normativas sem serem considerados marginais.

Para cumprir a função de "inserção" e "pertencimento" ao mundo ocidentalizado através do processo de escolarização de postura moderna, seria necessário que as crianças fossem capturadas pelos códigos normativos deste, se construíssem como sujeitos disciplinados e autogovernáveis, de forma que a docilização de seus corpos se tornasse imprescindível para circulação na sociedade envolvente urbana, que tem suas regras e normas bem estabelecidas. Aos que não as cumprem restaria a punição, a desvalorização ou mesmo a 
exclusão do grupo. Nesta perspectiva, volto a apoderar-me da reflexão antes construída, em que situo a escola como elemento "estrangeiro" à comunidade indígena, que tem como função principal a transmissão dos instrumentos e códigos simbólicos do mundo ocidental. Entre estes códigos, a disciplinarização desponta como importante ferramenta para compreensão e apreensão da organização espaço-temporal da sociedade envolvente. Neste aspecto, Veiga-Neto (2001) bem coloca a importância desta ferramenta para o mundo moderno, localizando a escola como instrumento de produção deste dispositivo: "Assim, se para vivermos civilizadamente no mundo moderno é mesmo necessário um mínimo de disciplinamento, então as crianças ainda devem ir à escola" (p. 9). É desta forma, apreendendo os modos de vida e capturados pelas rotinas e códigos disciplinares, lhes conferindo o pertencimento e aceitação na sociedade envolvente, que o índio compreende sua condição de agente de sua própria história. Somente dominando os códigos disciplinares da sociedade envolvente pode estabelecer negociações que (re)dimensionem sua identidade e sociedade.

Fica claro, nas vozes abaixo, que o Paresi entende que, sem o estabelecimento do comportamento disciplinar adequado, a criança não conseguirá construir os novos saberes, tão necessários para o convívio e negociações com a sociedade envolvente:

Atrapalha porque, se eles tiverem andando muito, às vezes eu estou explicando no quadro e eles não estão prestando atenção, aí isso dificulta muito a aprendizagem deles porque se eles não prestam atenção como é que eles vão aprender? (Professor índio de escola da aldeia)

Agora o professor, por exemplo, o professor da aldeia passa tarefa no quadro e os alunos ficam lá conversando com outro, não presta atenção no quadro, então nesses casos aí os aluno não aprende, aí o aluno não aprende mesmo porque ele não presta atenção no quadro, presta só na conversa deles. (Pai de aluno)

Nesse sentido, compreendo que o Paresi está subjetivado pela perspectiva da escola de princípios iluministas, apesar de todas as discussões que têm sido empreendidas nos últimos anos para a construção de uma escola diferenciada, que respeite e valorize os aspectos culturais do grupo. Na perspectiva dessa forma de "desejar" a escola de expressão moderna, na qual os aprendizes ocupam lugares, espaços determinados, dentro de uma organização temporal, segundo uma hierarquia de saberes a serem construídos, o Paresi expressa seu descontentamento pela desorganização dos alunos no ambiente escolar, ao falar da ineficiência no aprendizado na escola da aldeia, como aparece nos depoimentos abaixo:

\section{[...] eles não sentam! Eles saem toda hora lá fora... eles... vão na carteira do coleguinha, eles ficam fazendo bagunça. (Professor índio de escola da aldeia)}

\section{[...] Porque a criança faz muita bagunça na sala, né, e o professor fica assim no quadro explicando para eles... o professor escreve no quadro e eles não prestam atenção. (Pai de aluno)}

Este aspecto da importância de a criança ocupar "seu espaço específico", previamente determinado pelo professor e pela instituição, para desenvolver sua aprendizagem, está bem tratado por Foucault (2000) ao analisar os dispositivos que sustentam a disciplinarização de corpos e afirmar que "importa estabelecer as presenças e as ausências, saber onde e como encontrar os indivíduos, instaurar as comunicações úteis, interromper as outras, poder a cada instante vigiar o comportamento de cada um, apreciá-lo, sancioná-lo, medir as qualidades ou méritos" (p. 123). Não se estabelecendo esta ordem disciplinar, não "localizando" e controlando o corpo, o domínio sobre este não se configura; logo, o professor "perde" o controle do aprendiz e, por conseguinte, não estabelece a relação de controle de sua aprendizagem.

Esta questão da organização espacial, enquanto dispositivo de manutenção da ordem disciplinar, aparece como fator complicador, tendo em vista que o funcionamento da escola nas aldeias se caracteriza por salas multisseriadas, devido ao baixo número de 
alunos matriculados por série, nas quais alunos de diferentes idades se misturam na rotina escolar. Nesse aspecto encontramos também mais um elemento valorizado pela concepção moderna de escola, em que a organização e a distribuição dos alunos no espaço escolar revelam-se dispositivos imprescindíveis na construção e transmissão de saberes.

\section{A provocação}

Neste ponto quero me posicionar de forma a incitar os leitores ao debate. Proponho-me a ser "advogado do diabo", mexendo com as certezas e a tranqüilidade de quem discute e propõe ações em educação para índios.

Há anos, em nossa sociedade, vimos discutindo o modelo de escola importado de outros países e em oferta para a população nacional, entendendo que a escola deve trabalhar e privilegiar as experiências do alunado. São anos de discussões e, também em nossa cultura ocidentalizada, ainda não conseguimos delimitar e desenhar o modelo de escola que queremos e precisamos, de forma que ainda repetimos, de uma forma geral, o modelo tradicional de educação escolar.

$\mathrm{O}$ aspecto que primeiramente quero considerar se refere às diferentes configurações dos diversos grupos indígenas de nosso país. Nesta perspectiva, ao se tratar da educação indígena e propor modelos para funcionamento das escolas nas aldeias, há que se caracterizar a condição de vivência de cada grupo. Não basta utilizar modelos de outros grupos que tiveram sucesso na implantação de novos modelos educacionais. Cada grupo tem sua história e suas necessidades ante a situação de contato com a sociedade ocidentalizada. Com nossos valores do que entendemos de "escola necessária" para índios, considerando o "resgate das culturas tradicionais", podemos estar repetindo o modelo iluminista, invertendo porém valores do que é considerado "bom" e "necessário". Passamos da valorização do padrão ocidental do conhecimento científico para a valorização exacerbada dos saberes tradicionais. Na tentativa de valorizar as diferenças, talvez estejamos a continuar um processo de padronização, de homogeneização do que se entende que seja a educação indígena e a que ela se presta.

Insistimos em nosso discurso sobre escola diferenciada, valorização da língua materna, valorização dos aspectos culturais tradicionais para as escolas das aldeias. Não discuto, muito menos discordo, que seja necessária uma escola que atenda às necessidades das comunidades; proponho, sim, que seja necessário compreender que condições produziram as atuais configurações de um determinado grupo que, por conseguinte, tem perspectivas e desejos específicos para suas comunidades. É compreendendo as condições que possibilitaram a constituição de um grupo que se pode entender a real necessidade da comunidade, e não discursar sobre um modelo que, para a sociedade ocidentalizada, tem-se representado como necessário. Ora: os valores simbólicos, o que é "bom" ou "ruim" para a sociedade ocidentalizada, vem sendo construído ao longo dos anos, num contínuo processo de ressignificações. As mudanças não ocorrem simplesmente por decreto-lei, não são ensinadas; são construídas num processo mais amplo e nunca são definitivas.

As comunidades indígenas contam com a escola como instrumento de transmissão do que não é naturalmente construído no seio de sua cultura tradicional. A escola, assim, deveria fornecer-lhes as ferramentas necessárias para o trânsito, sem discriminações, na cultura ocidentalizada. Nesse sentido, a escola é "estrangeira" e deveria trabalhar com os códigos simbólicos do "estrangeiro". Sendo a escola um instrumento do ocidental, inserido nas suas aldeias, as coisas de índio não deveriam ser "ensinadas" na escola, principalmente para as culturas que ainda mantêm seus aspectos culturais tradicionais vivos. Quando o sistema escolar se propõe a trabalhar os aspectos culturais dos grupos indígenas, como artesanato e mitos, a escola poderia estar reconhecendo e aceitando a incapacidade do grupo em cumprir com uma função que é somente sua: a de trabalhar com seus aspectos muito particulares. Nesse sentido, poderia não estar reconhecendo a sabedoria, a valorização e a capacidade 
dos mais velhos, a quem é de direito a transmissão dos aspectos da cultura tradicional, de tal forma a ferir o orgulho e a vaidade das identidades culturais.

Em se tratando da metodologia a ser trabalhada na escola da aldeia, é corrente nos projetos de implantação de modelos de escolarização a afirmação de valorização da pedagogia indígena. Em conversas com diversos grupos indígenas, verificamos que a criança aprende a ser índio na execução de suas tarefas e observando os mais velhos. Nesse sentido, sim, a escola deveria propor uma metodologia centrada na atividade. Por outro lado, também devemos compreender que a repetição é uma atitude natural e cultural dos grupos indígenas. Para se transmitir os mitos, o mais velho repete para os mais novos, inúmeras vezes, seguidamente, uma mesma história, como fazem os velhos Paresi. Nesta perspectiva, um modelo de escola centrada em metodologias flexíveis não estaria contemplando o que entendemos por respeito às pedagogias próprias de cada grupo. Talvez este aspecto viria a explicar o fato de, apesar das discussões sobre metodologias diferenciadas, ainda os professores das escolas das aldeias continuarem em práticas tradicionais de repetições dos exercícios, como verifiquei em minha investigação.

Durante o desenvolvimento do Projeto Tucum, já referido anteriormente neste texto, encontramos muitas famílias das comunidades indígenas que não acreditam numa escola diferenciada, que valorize os aspectos culturais como conteúdos curriculares das escolas da aldeia. Para estas famílias, a configuração de escola diferenciada não atende ao necessário para a criança sobreviver no atual contexto de mundo exterior à aldeia. A representação de escola, construída no interior destas comunidades, refere-se a uma escola que discipline e que ensine rigorosamente os conteúdos que lhes permitirão acesso, em iguais condições aos demais cidadãos brasileiros, a todos os sistemas valorizados ocidentalmente. Claro que para nossa sociedade o modelo atual de escola, ainda centrado em conteúdos, a princípio desnecessários para o uso rotineiro, a despeito de esforços repetidos de mudança de metodologias e concepções, também não está aten- dendo ao que entendemos de necessário para construção de uma realidade mais equilibrada socialmente; mas esta é a nossa história, e não a das comunidades indígenas.

As comunidades indígenas têm visto, freqüentemente, que a maioria das pessoas de sucesso também teve uma história escolar construída sob a perspectiva de um currículo de conteúdos cobrados rigorosamente. Os concursos públicos, os vestibulares, por exemplo, ainda continuam selecionando candidatos em função de um determinado conhecimento acumulado. Não devemos esquecer que os índios não ficarão "cercados" em suas aldeias eternamente; aliás, já assinalei anteriormente a questão dos fluxos migratórios e as novas exigências em função destes. Também é inegável que, diante das novas condições de contato com a sociedade ocidentalizada, novas necessidades aparecem para as comunidades indígenas que com maior freqüência se inserem no mercado de trabalho nas cidades, até mesmo para a própria sobrevivência.

A mídia não se cansa de mostrar inúmeros programas de atendimento à população analfabeta, buscando fórmulas de combate aos altos índices de analfabetismo, deixando claro que o processo de escolarização é imprescindível na atual sociedade. Os governos têm implementado numerosos programas que incentivam e permitem o acesso do maior número possível de pessoas aos processos de escolarização. As oportunidades e oferta de emprego têm privilegiado pessoas portadoras de certificado de conclusão de ensino fundamental e médio. Quanto mais qualificado o serviço, maior a exigência do conhecimento escolar. Nossa sociedade deixa clara e pública a valorização do conhecimento escolar para a população; na verdade, poderíamos falar de um certo "acúmulo de conhecimentos escolares" para se ter acesso a uma série de bens de direito, como um emprego, por exemplo. Mas o que preconizamos para os índios? Dizemos a eles que o acúmulo de conteúdos não é significativo! Claro que eles nos olham e nos ouvem com desconfiança, pois compreendem que a maioria das escolas do sistema nacional ainda valoriza o "acúmulo de sabe- 
res escolares". Talvez eles considerem que estão, mais uma vez, sendo enganados pelos brancos. Se a escola específica e diferenciada é tão boa assim, por que esta configuração de escola não estaria presente, de forma expressiva, em nossa sociedade ocidentalizada?

Não quero aqui propagar ou mesmo compartilhar da idéia da padronização dos modelos escolares, sob a perspectiva ocidental; ao contrário, quero deixar clara a necessidade de se compreender a construção cultural de cada grupo ao se propor a educação escolar para índios. A inserção da escola nas comunidades indígenas deu-se a partir de sua representação como instituição responsável para transformação do índio em "homem civilizado", como um instrumento de inserção deste "selvagem" no mundo ocidental. A idéia da escola enquanto instrumento de inserção e assimilação foi sendo construída ao longo dos anos e não se apaga num piscar de olhos! Como já apontei anteriormente, as mudanças ocorrem em um processo de longo prazo, e não por simples decreto-lei; elas são construídas no dia-a-dia de uma sociedade, ainda que não as notemos. Talvez somente as gerações futuras possam perceber como se deram.

Como vim apontando neste texto, a escola na aldeia é um instrumento do outro, com uma função específica: a de informar sobre a dinâmica da sociedade deste outro. Dessa forma, penso ser necessário discutir-se mais profunda e amplamente com as pessoas das comunidades indígenas, não só com líderes ou representantes, a formatação de escola e currículo de que necessitam. Quando levamos às comunidades indígenas nossa visão de escola necessária não estaríamos continuando a nos sobrepor à vontade e necessidade deles? Apesar de nosso discurso de respeito às características tradicionais de cada povo, não estaríamos ainda "ditando" o que é "bom ou ruim" para eles? Praticamos o jogo do poder do discurso e da construção de significados de mundo. Em certo sentido, trocamos os elementos, as palavras, mas continuamos a estabelecer uma relação de soberania, deixando claro que "nós" podemos dizer o que é certo e o que não é. Falar de diferença é considerar o que pensam, o que significam do mundo, o que constroem de valores. Falar de diferença é compreender as características dos sujeitos e dos diversos grupos. Talvez fosse melhor não falar da diferença, mas deixar a diferença falar. Não estaríamos assinando um contrato psicológico de que temos que falar da diferença, e por ela, porque construímos uma representação de que ela não consegue falar? É incapaz? Neste sentido, há que se posicionar desconfiante com o que imaginamos e informamos ser o "certo" para uma determinada cultura, mesmo porque "nós" é que estamos falando, e não as pessoas da cultura da qual falamos. Assim, ainda usamos o jogo do poder, mesmo que pelo discurso das especificidades e da diferença: continuamos a estabelecer verdades, mesmo que em um outro olhar.

MARIA HELENA RODRIGUES PAES, mestre em educação pela Universidade Federal do Rio Grande do Sul - UFRGS, é docente do Departamento de Letras da Universidade do Estado de Mato Grosso - UNEMAT, Campus de Tangará da Serra. Atualmente integra um grupo de pesquisa da Faculdade de Educação dessa universidade que investiga o tema "Artefatos culturais e sociedade contemporânea: estudos sobre discursos como territórios de produção de significados e de constituição de subjetividades". Neste projeto, é responsável pela investigação intitulada "Análise dos discursos de professores e pessoal administrativo das escolas públicas do ensino regular sobre alunos índios egressos de escolas das aldeias Paresi de Tangará da Serra - MT”. Publicou vários textos inspirados na investigação que realizou durante o mestrado, entre os quais se destacam: A questão da língua nos atuais dilemas da escola indígena em Aldeias Paresi de Tangará da Serra (Revista Brasileira de Educação $\mathrm{n}^{\circ}$ 21, set.-dez. 2002, p. 52-60); A escolarização: um processo de produção de identidades híbridas (Anais do XI ENDIPE - Encontro Nacional de Didática e Prática de Ensino: Igualdade e Diversidade na Educação, 2001.E-mail:mhninha@terra.com.br

\section{Referências bibliográficas}

ARELLANOS, Vilma Duque, FREEDSON-GONZÁLES, Margaret, (1998). Hacia un diagnóstico de la realidad educativa de los pueblos indígenas de la región mesoamericana: el caso de los Altos Chiapas, México. In: CONFERÊNCIA 
AMERÍNDIA DE EDUCAÇÃO. CONGRESSO DE PROFESSORES INDÍGENAS DO BRASIL. Anais... Cuiabá: Secretaria de Estado de Educação/Conselho de Educação Escolar Indígena de Mato Grosso, p. 79.

BANDEIRA, Maria de Lourdes, (1997). Formação de professores índios: limites e possibilidades. In: SECCHI, Darci, (org.) Urucum, jenipapo e giz. Cuiabá: Entrelinhas, p. 35.

BONIN, Iara Tatiana, (1998). Professores indígenas: resistência em movimento. In: CONFERÊNCIA AMERÍNDIA DE EDUCAÇÃO. CONGRESSO DE PROFESSORES INDÍGENAS DO BRASIL. Anais... Cuiabá: Secretaria de Estado de Educação/ Conselho de Educação Escolar Indígena de Mato Grosso, p. 131.

BRASIL, MEC, (1998). Referencial curricular nacional para as escolas indígenas. Brasília: MEC / SEF.

CANCLINI, Néstor G. (1997). Culturas híbridas. Estratégias para entrar e sair da modernidade. São Paulo: EDUSP. Tradução de Ana Regina Lessa e Heloísa Pezza Cintrão.

, (2000). Notícias recientes sobre la hibridación. Disponível em: 〈www://acd.ufrj.br/pacc/artelatina/nestor.html> Acesso em: 14 dez. 2000.

COSTA, Marisa Vorraber, (2000). Estudos culturais - para além das fronteiras disciplinares. $I n$ : , (org.). Estudos culturais em educação. Mídia, arquitetura, brinquedo, biologia, literatura, cinema. Porto Alegre: Editora da UFRGS, p. 13-36.
FOUCAULT, Michel, (2000). Vigiar e punir : nascimento da prisão. 22a ed. Petrópolis: Vozes. Tradução de Raquel Ramalhete.

HALL, Stuart, (1997). A centralidade da cultura: notas sobre as revoluções de nosso tempo. Educação e Realidade, Porto Alegre: UFRGS, v. 22, n 22 , p. 15-46. , (2000). A identidade cultural na pós-modernidade. $4^{a}$ ed. Rio de Janeiro: DP\&A. Tradução de Tomaz Tadeu da Silva e Guacira Lopes Louro.

SARLO, Beatriz, (1997). Cenas da vida pós-moderna: intelectuais, arte e vídeo-cultura na Argentina. Rio de Janeiro: Editora UFRJ.

SILVA, Rosa Helena Dias da, (2000). A autonomia como valor e articulação de possibilidades: o movimento dos professores indígenas do Amazonas, de Roraima e do Acre e a construção de uma política de educação escolar indígena. Cadernos $C E$ DES, n ${ }^{\circ}$, Campinas, CEDES, p. 62-75.

VEIGA-NETO, Alfredo José, (2000). Michel Foucault e os estudos culturais. In: COSTA, Marisa Vorraber, (org.) Estudos culturais em educação. Porto Alegre: Editora da UFRGS, p. 37-69.

, (2001). Espaços, tempos e disciplinas: as crianças ainda devem ir à escola? In: CANDAU, Vera Maria, (org.) Linguagens, espaços e tempos no ensinar e aprender. $2^{\mathrm{a}} \mathrm{ed}$. Rio de Janeiro: DP\&A.

Recebido em fevereiro de 2003

Aprovado em março de 2003 